Proc. Indian Acad. Sci. (Chem. Sci.), Vol. 102, No. 5, October 1990, pp. 721-723.

(C) Printed in India.

\title{
Temperature and radiation effects on the Raman bands of epoxy resin
}

\author{
V JANARTHANAN and G THYAGARAJAN* \\ Department of Physics, Indian Institute of Technology, Powai, Bombay 400076, India
}

\begin{abstract}
The C-H stretching, in-plane bending and out-of-plane bending modes of epoxy resin are investigated using Raman spectroscopy. Changes in Raman frequencies show a weakening of the hydrogen bonds on heating, but no effect on irradiation up to a total dose of $16 \mathrm{Mrad}$.
\end{abstract}

Keywords. Raman spectra of epoxy resins; temperature and irradiation effects.

\section{Introduction}

The effect of temperature on phenoxy resin (Coleman and Moskala 1983) and the effects of solvent and temperature on epoxy resin (Janarthanan and Thyagarajan 1988) has been studied by FTIR spectroscopy. In both cases, the band at about $3400 \mathrm{~cm}^{-1}$, attributed to a wide distribution of hydrogen-bonded hydroxyl-stretching frequencies, shifts to higher frequencies, indicating a weakening of the hydrogen bonds. The aim of the present work is to study the temperature and radiation effects on some of the Raman bands of epoxy resin.

\section{Experimental}

The epoxy resin used in this study was obtained from Ciba-Geigy. The Raman bands were recorded using a 4-watt Argon ion laser and a Jobin-Yvon Ramanor spectrometer. The slit width used was $220 \mu$ and the spectra were recorded with a scan speed of $20 \mathrm{~cm}^{-1} / \mathrm{min}$. Before recording the spectra, the sample was exposed to laser beams for three hours to quench the fluorescence. A temperature cell was used for high temperature studies with an accuracy of $\pm 1{ }^{\circ} \mathrm{C}$. For irradiation studies, the sample was irradiated in a $\gamma$-ray chamber by a ${ }^{60} \mathrm{Co}$ source with a dose rate of $0 \cdot 39 \mathrm{Mrad} / \mathrm{h}$. The sample was irradiated with a total dose of $16 \mathrm{Mrad}$.

\section{Results and discussion}

The prominent bands at 3080,1262 and $831 \mathrm{~cm}^{-1}$ were studied. The $\mathrm{O}-\mathrm{H}$ stretching frequency expected at about $3400 \mathrm{~cm}^{-1}$ as in IR is probably very weak and could

\footnotetext{
* For correspondence
} 


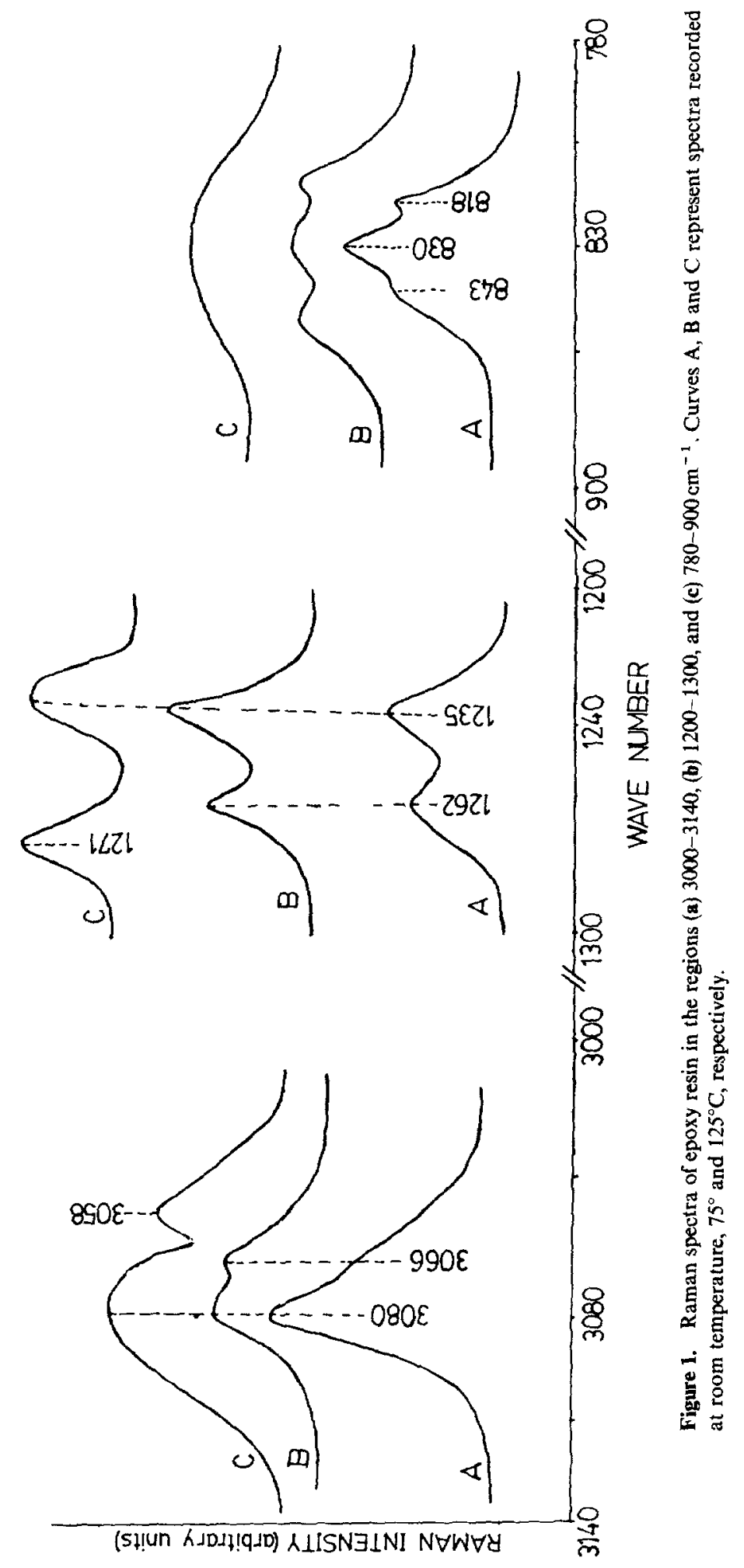


not be recorded. Figure 1a shows the Raman spectrum of epoxy in the region $3000-3140 \mathrm{~cm}^{-1}$ recorded at room temperature, $75^{\circ} \mathrm{C}$ and $125^{\circ} \mathrm{C}$ (curves $\mathrm{A}, \mathrm{B}$ and $\mathrm{C}$ respectively). It has been observed that the band at $3080 \mathrm{~cm}^{-1}$ assigned (Martzel and Koenig 1986) to the stretching of the phenyl-hydrogen bond undergoes reduction in intensity as the temperature increases. Further a shoulder at $3066 \mathrm{~cm}^{-1}$ develops distinctly which shifts to lower frequency (figure 1c) as the temperature increases indicating the weakening of the phenyl-hydrogen bond.

In figure 1c the Raman spectra recorded in the region $780-900 \mathrm{~cm}^{-1}$ at room temperature, 75 and $125^{\circ} \mathrm{C}$ (curves $\mathrm{A}, \mathrm{B}$ and $\mathrm{C}$ respectively) are shown. Three bands with peaks at 818,830 and $843 \mathrm{~cm}^{-1}$ attributed to the phenyl-hydrogen out-of-plane bending are distinctly observed at room temperature. As the temperature increases to $75^{\circ} \mathrm{C}$, the bands become broader and the peak intensity is reduced. At $125^{\circ} \mathrm{C}$, the bands merge and give a very broad profile with much reduced peak intensity. This indicates the sensitivity of the out-of-plane vibrations to temperature changes.

In figure $1 \mathrm{~b}$, the bands in the region $1200-1300 \mathrm{~cm}^{-1}$ are shown. At room temperature, there are two bands at 1235 and at $1262 \mathrm{~cm}^{-1}$ (curve A). The band at $1235 \mathrm{~cm}^{-1}$ is assigned to the phenyl-hydrogen in-plane bending while the one at $1262 \mathrm{~cm}^{-1}$ is attributed to the epoxy ring (Martzel and Koenig 1986). It may be noted that the band at $1262 \mathrm{~cm}^{-1}$ is sensitive to temperature changes as can be seen from the frequency shift and intensity increase (curve c) whereas that at $1235 \mathrm{~cm}^{-1}$ shows only an increase in intensity but no shift in frequency. Since the changes in frequency and intensity in all the bands are indicative of the weakening of the bands, the origin of the changes can be traced to decomposition rather than structural changes.

The epoxy resin was irradiated by $\gamma$-radiation to a total dose of $16 \mathrm{Mrad}$ in air. The Raman profiles of the irradiated sample showed no changes implying that the high energy radiation does not have any effect on the sample for a dose rate of 16 Mrads.

\section{References}

Coleman M M and Moskala E J 1983 Polymer 24251

Janarthanan V and Thyagarajan G 1988 J. Polym. Sci., Polym. Phys. Ed. 262127

Martzel E and Koenig J L 1986 Adv. Polym. Sci. 7579 